\title{
A APLICAÇÃO DA CONVENÇÃO DE NOVA IORQUE DE 1958 NO BRASIL
}

\section{THE APPLICATION OF THE 1958'S NEW YORK CONVENTION IN BRAZIL}

\author{
${ }^{1}$ Karina Lie Yoshii
}

\section{RESUMO}

A ascendente prática do comércio internacional resultou no aumento do número de controvérsias, as quais são eventuais quando se lida com contratos e relações comerciais. Nesse contexto, mister a padronização da arbitragem, tendo em vista as divergências das leis nacionais. Por isso a importância da Convenção de Nova Iorque, que trouxe mecanismos para uniformizar os regramentos referentes à solução de conflitos pela arbitragem. No entanto, foi tardia a ratificação do Brasil, ocorrendo apenas em 2002, e mesmo após ratificada, há o questionamento sobre a aplicação efetiva da Convenção pelo Poder Judiciário brasileiro, visto a existência da Lei de Arbitragem Brasileira.

Palavras-chave: Convenção de nova iorque, Arbitragem internacional, Comércio internacional

\begin{abstract}
The ascending international commerce results in the rise of the number of controversies, that are part of the day-to-day of the world of international business. In the international commerce the standardization of the arbitration process is vital considering the difference between national laws. That's why the New York Convention is important given the procedures to standardize the rules about the solution of the disputes. Nevertheless Brazil's ratification was belated, occuring only in 2002, and even after the ratification there's a discussion about the efective application of the Convention by the brazilian Judiciary, given the existence of the brazilian arbitration law.
\end{abstract}

Keywords: The new york convention, International commerce, International arbitration

\footnotetext{
${ }^{1}$ Mestranda em Direito (Franca) na Universidade Estadual Paulista Júlio de Mesquita Filho - UNESP, São Paulo, SP. (Brasil). E-mail: lieyoshii11@gmail.com
} 


\section{INTRODUÇÃO}

O comércio internacional sofreu um grande crescimento, especialmente no cenário do pós Segunda Guerra Mundial. O processo de globalização tornou os mercados mais acessíveis, permitindo o desenvolvimento do mercado mundial.

No contexto da Nova Ordem Mundial, os laços criados entre os mercados dos países os tornaram dependentes uns dos outros, uma vez que nenhum país é autossuficiente. A multipolaridade do sistema global da atualidade e a ascensão dos países do chamado "terceiro mundo" acabaram gerando dinamicidade às relações comerciais internacionais e o surgimento de potenciais mercados consumidores.

Nenhum país é capaz de conter todos os produtos do mercado global, havendo que importar o que lhe falta ou o que não lhe é suficiente. Assim, surge uma circulação de bens, pessoas, tecnologia e dinheiro. Isso leva à criação de regras para o mercado internacional, dando origem a um sistema internacional de circulação de moedas e pagamentos internacionais.

No entanto, as eventuais controvérsias que surgem com as relações comerciais também aumentaram, gerando a necessidade de criação de um mecanismo imparcial e célere, a fim de não desestimular o desenvolvimento do comércio internacional.

Emerge, assim, a arbitragem internacional como principal meio de solução de conflitos internacionais, pois é vista como mais rápida e menos custosa - o que pode ser uma ideia errônea, visto que depende das diligências que o caso concreto demanda para ser solucionada. A confidencialidade é um quesito muito procurado pelas partes do procedimento arbitral, favorecendo a utilização da arbitragem para dirimir os conflitos.

Além disso, graças à Convenção de Nova Iorque de 1958, as sentenças arbitrais são mais fáceis de serem executadas, garantindo, também, a imparcialidade da decisão, visto que as partes possuem autonomia para escolherem como resolverão suas controvérsias, não estando mais à mercê de seus tribunais nacionais, eliminando a desconfiança e proporcionando uma maior segurança à formação de uma solução justa.

A Convenção de Nova Iorque, aprovada pelas Nações Unidas em 10 de junho de 1958, é um importante instrumento de solução de litígios comerciais, pois revolucionou a arbitragem ao facilitar a circulação de decisões arbitrais, incentivando o desenvolvimento e crescimento do comércio internacional. 
Ademais, veio a inspirar o texto de novas leis nacionais, como a Lei $\mathrm{n}^{\mathbf{0}}$ 9.307/96 -

a Lei de Arbitragem Brasileira, a qual segue a linha e o objetivo da Convenção de Nova Iorque, inovando em alguns pontos.

A referida lei brasileira tem grande importância, ainda mais quando o Brasil não havia ratificado a Convenção. No entanto, constata-se que o STJ, mesmo após a ratificação da Convenção de Nova Iorque em 2002, não mudou o embasamento de suas decisões, apoiandose quase que exclusivamente na lei brasileira.

Apesar de a Lei no 9.307/96 ser baseada na Convenção, há dispositivos que abrem espaço para interpretação diversa, interferindo na uniformização da arbitragem comercial internacional que é tão buscada pela Convenção.

O objeto desse estudo envolve analisar as diferenças e semelhanças da Convenção de Nova Iorque em relação à Lei de Arbitragem Brasileira, não visando apresentar conclusões sobre qual seria superior. Busca-se apresentar interpretações de ambas a fim de averiguar se a ratificação da Convenção pelo Brasil foi um gesto meramente formal ou se seu uso se faz efetivo no país.

A pesquisa jurídica caracteriza-se pelo pluralismo metodológico, visando garantir maior objetividade e complexada ao estudo. Desta forma, a presente pesquisa adota, em razão de ser um estudo teórico-jurídico, o método histórico analítico, uma vez que se pretende, através do resgate histórico, compreender situações e o arcabouço legal na atualidade, além do método comparativo. Quanto à tipologia, a pesquisa será bibliográfica e documental, uma vez que a condução da pesquisa é proporcionada pela leitura de livros, artigos e teses, além de documentos legais referentes ao tema, principalmente Tratados e Convenções, que compõem o ponto de partida e cerne das discussões.

\section{A APLICAÇÃO DA CONVENÇÃO DE NOVA IORQUE NO BRASIL}

O Brasil conquistou o título de "belle of the ball" da arbitragem internacional pela Global Arbitration Review, destacando-se por sua performance ligada, principalmente, no cumprimento de sentenças arbitrais estrangeiras (BERG, 2013).

O destaque do Brasil surpreende por causa da tardia ratificação da Convenção de Nova Iorque, que ocorreu apenas em 2002. Curioso fato é o de que o Poder Judiciário brasileiro, mesmo após a ratificação, raramente faz menção à Convenção nos julgados, continuando a aplicar a Lei de Arbitragem de 1996.

Essa postura é fortemente criticada pelo professor Albert Jan van den Berg (BERG, 2013), uma vez que um dos objetivos da Convenção é criar um regulamento preciso e 
uniforme, havendo uma desconfiança quanto à contribuição do Brasil para alcançar essa meta, tendo em vista o contínuo emprego da lei brasileira ao invés da Convenção.

Em pesquisa realizada de acordo com o banco de dados jurisprudencial do STJ, a fim de averiguar a aplicação da Convenção de Nova Iorque e as características que regem a arbitragem no Brasil, conclui-se que a referência expressa à Convenção é rara nas decisões do STJ. Segundo o levantamento de dados referentes à jurisprudência nacional, 91,6\% das decisões são fundamentadas pela Lei $\mathrm{n}^{\circ}$ 9.307/96, ao passo que apenas 8,3\% fazem menção expressa à Convenção de Nova Iorque (LOPES; CARVALHO, 2013).

Embora se entenda que, após a ratificação da Convenção de Nova Iorque, as decisões de homologação de sentenças arbitrais estrangeiras devessem fundamentar-se neste tratado, verifica-se que tal posicionamento não está sendo adotado pelo STJ, visto sua semelhança com os arts. 38 e 39 da Lei $9.307 / 96$ e o art. V da Convenção de Nova Iorque.

O maior obstáculo para atingir tal objetivo é a interpretação aplicada à Convenção em cada país. Em regra, a Convenção de Nova Iorque é um tratado internacional, devendo ser interpretado de acordo com os devidos regulamentos, especialmente com a Convenção de Viena de 1969, ratificada pelo Brasil em 2009 - Decreto Legislativo nº 496/2009 (BRASIL, 2009). Entretanto, os países não aplicam o disposto nos arts. 31 a 33 da Convenção de Viena, acabando por interpretar a Convenção de Nova Iorque como um estatuto, abrindo espaço para diferentes visões.

O professor Albert Jan van den Berg, juntamente com o professor Pieter Sanders um dos fundadores da Convenção de Nova Iorque - acreditam que, mesmo com a simplicidade do texto, o objetivo de criar um regulamento internacionalmente uniforme não foi atingido. Os professores organizaram enxertos de decisões envolvendo a Convenção nos países que a ratificaram em anuários e, ao analisá-los, puderam ver que, nos volumes mais recentes, as interpretações dos países contratantes tendem a seguir as que já foram expostas nos anuários passados, colaborando para o alcance do objetivo aludido.

O texto da Convenção não é totalmente claro e exato, existindo as lacunas, dando espaço a diferentes interpretações, analisadas nos anuários. No entanto, nenhum Estado que haja ratificado a Convenção é obrigado a seguir a interpretação dos outros países. É apenas uma questão de cortesia, podendo o Estado preencher as lacunas de maneiras divergentes às anteriormente discutidas.A Lei de Arbitragem brasileira entrou em vigor em 1996, sendo aplicada por oito anos antes da ratificação da Convenção de Nova Iorque. Desse modo, as questões da homologação de sentença estrangeira eram decididas com base nos arts. 34 a 40 da referida lei. Apesar de muito similares, as disposições da Lei n ${ }^{\circ}$ 9.307/96 não são idênticas às da Convenção de Nova Iorque e, mesmo após a ratificação desta, das 40 decisões 
sobre homologação de sentença estrangeira posteriores a 2002, quase todas foram decididas de acordo com a lei nacional (BERG, 2013).

Esses dados divergem da expectativa convencional, uma vez que se esperava que após a ratificação da Convenção pelo Brasil, haveria uma migração do embasamento legal para esta. Todavia, pelas decisões analisadas, os tribunais brasileiros, em especial o STJ, não fazem referência à Convenção de Nova Iorque e, muito menos, aplicam-na.

Além da expectativa, essa tendência vai contra o que expõe o art. 34 da Lei de Arbitragem, visto que elege como hierarquicamente superior ao seu texto o disposto no tratado internacional que possui eficácia no território nacional, sendo aplicável a lei brasileira quando não houver tal tratado (BRASIL, 1996).

As decisões arbitrais não trazem respostas exatas para essa preferência no uso da Lei de Arbitragem brasileira. Pode-se dizer que os operadores do Direito se acostumaram com o uso dela nos oitos anos que a separam da ratificação da Convenção de Nova Iorque, ou que consideram as disposições de ambas idênticas. Há outros possíveis motivos, como a preferência do Poder Judiciário brasileiro para uma lei nacional. Além disso, há interpretações que aplicam o art. VII da Convenção por implicação, estabelecendo a aplicação da lei brasileira por esta se apresentar mais vantajosa no determinado caso concreto.

No entanto, a omissão na aplicação da Convenção - o que primeiramente parece inofensivo - pode, com o tempo, levar a arbitragem no Brasil a um rumo divergente dos outros países ratificadores da Convenção de Nova Iorque.

\section{CONVENÇÃO DE NOVA IORQUE E LEI No 9.307/96: SEMELHANÇAS E DIFERENÇAS}

\subsection{Escopo de aplicação}

A Convenção de Nova Iorque, também chamada de Convenção sobre o Reconhecimento e Execução de Sentenças Arbitrais Estrangeiras, primeiramente delimita seu escopo de aplicação. O artigo I da Convenção de Nova Iorque estabelece em seu parágrafo 1 as duas definições de sentença arbitral estrangeira.

Define-se como sentença arbitral estrangeira aquela que se deu em território divergente da onde o reconhecimento e a execução serão cumpridos. Já a segunda definição abrange a sentença que não é considerada doméstica no Estado que deverá ser reconhecida e executada. ${ }^{1}$

1 Art. I. 1. A presente Convenção aplicar-se-á ao reconhecimento e à execução de sentenças arbitrais estrangeiras proferidas no território de um Estado que não o Estado em que se tencione o reconhecimento e a 
A segunda parte do parágrafo 1 permite que os Estados ratificadores interpretem segundo seus critérios o que constituiria uma sentença não considerada doméstica, dependendo, assim, da discricionariedade dos países contratantes.

$\mathrm{O}$ art. 34 da Lei $n^{\circ}$ 9.307/96 contempla a primeira definição da Convenção, confirmando a regra segundo a territorialidade. O entendimento do STJ também vai de acordo, como se depreende do caso entre Nuovo Pignone contra Petromec et al. Neste caso, o processo arbitral foi instaurado na cidade do Rio de Janeiro sob as regras de arbitragem da Câmara Internacional do Comércio. Assim, o procedimento foi conduzido em língua portuguesa e o árbitro brasileiro, após analisar o caso devidamente, pronunciou uma sentença. Quando a parte requerente buscou a execução da sentença em território brasileiro, a requerida se opôs, argumentando que a sentença prolatada pela CIC era internacional, devendo ser reconhecida perante o STJ antes de iniciar a execução. O caso chegou ao STJ, o qual decidiu pelo sistema territorial do art. 34 da Lei 9.307/96. Portanto, mesmo que o requerimento para a arbitragem tenha sido feito perante a CIC e conforme suas regras, não alterou a nacionalidade da sentença, já que foi realizada na cidade do Rio de Janeiro, de acordo com o que as partes haviam estipulado (BRASIL, 2011).

A decisão exposta está inteiramente de acordo com o que estipula a Convenção de Nova Iorque, mesmo não havendo menção desta na sentença. Não há dúvidas que o art. 34 da Lei de Arbitragem Brasileira contribui para a aplicação uniforme da Convenção, tornando-se mais vantajosa por delimitar a definição de sentença arbitral de acordo com o quesito puramente territorial, não abrindo lacunas para outras interpretações de sentenças nãodomésticas.

\subsection{O requisito do acordo escrito}

Os dois primeiros parágrafos do art. II da Convenção tratam do acordo escrito, como se mostra a seguir (BRASIL, 2002):

1. Cada Estado signatário deverá reconhecer o acordo escrito pelo qual as partes se comprometem a submeter à arbitragem todas as divergências que tenham surgido ou que possam vir a surgir entre si no que diz respeito a um relacionamento jurídico definido, seja ele contratual ou não, com relação a uma matéria passível de solução mediante arbitragem.

execução de tais sentenças, oriundas de divergências entre pessoas, sejam elas físicas ou jurídicas. A Convenção aplicar-se-á igualmente a sentenças arbitrais não consideradas como sentenças domésticas no Estado onde se tencione o seu reconhecimento e a sua execução. ORGANIZAÇÃO DAS NAÇÕES UNIDAS. Convenção sobre o Reconhecimento e a Execução de Sentenças Arbitrais Estrangeiras. Nova York, 1958. Disponível em: <http://www.planalto.gov.br/ccivil_03/decreto/2002/D4311.htm>. Acesso em: 24 set. 2015. 
2. Entender-se-á por "acordo escrito" uma cláusula arbitral inserida em contrato ou acordo de arbitragem, firmado pelas partes ou contido em troca de cartas ou telegramas.

Conforme o parágrafo 1, os Estados devem reconhecer o acordo escrito que forma o compromisso das partes a resolver suas controvérsias por meio da arbitragem. Referido acordo inclui o compromisso arbitral e a cláusula compromissória.

No Brasil, foi a Lei n ${ }^{\circ}$ 9.307/96 que possibilitou essa forma de convenção arbitral, uma vez que, antes dela, o descumprimento da cláusula compromissória - que faz relação a eventos futuros - não possuía os mesmos efeitos do descumprimento do compromisso arbitral - relativo aos conflitos já instaurados.

Assim dispõe o art. $3^{\circ}$ da Lei $n^{\circ}$ 9.307/96: “Art. $3^{\circ}$ As partes interessadas podem submeter a solução de seus litígios ao juízo arbitral mediante convenção de arbitragem, assim entendida a cláusula compromissória e o compromisso arbitral.” (BRASIL, 1996).

Quanto ao parágrafo 2, tanto para a execução de sentença arbitral estrangeira quanto para execução de convenção arbitral, existe o requerimento de que sejam escritos. A definição proposta pelo parágrafo 2 provê duas alternativas: acordo escrito como cláusula em contrato ou em convenção à parte que foram devidamente assinadas pelas partes; e, também, cláusula em contrato ou em convenção separada contidas na troca de correspondências entre as partes.

Esse parágrafo é causador de muitas controvérsias aos aplicadores da Convenção, uma vez que não prevê a aceitação tácita, levando ao indeferimento de execuções em vários casos. Deve-se entender que o contexto do comércio à época da elaboração da Convenção de Nova Iorque é bem diferente do atual, levando a interpretações que atualizem o texto sem que o intuito da Convenção seja perdido.

Assim, atualmente existe a abordagem que estabelece que, ao realizar a troca de documentos, entende-se que nenhuma das partes se opôs ao que foi estabelecido nos mesmos, aceitando, assim, o inteiro teor do contrato. Devido às controvérsias geradas, a UNCITRAL Working Group II lançou uma recomendação a fim de que o art. II, parágrafo 2, não fosse interpretado de forma exaustiva, tornando o requerimento escrito uma das possíveis formas. No entanto, essa é apenas uma recomendação, sendo importante o entendimento uniforme dos Estados que aplicam a Convenção de Nova Iorque.

O STJ utiliza, majoritariamente, o art. $4^{\circ}$ da Lei de Arbitragem Brasileira para a questão, tendo feito referência ao disposto no art. II da Convenção uma vez, no caso que envolvia a empresa argentina Oleaginosa Moreno Hermanos Sociedad Anónima Comercial 
Industrial Financiera Inmobiliaria y Agropecuaria e a empresa brasileira Moinho Paulista

LTDA. No entanto, o texto do art. $4^{\circ}$ diverge do da Convenção, como mostrado abaixo:

\begin{abstract}
Art. $4^{\circ}$ A cláusula compromissória é a convenção através da qual as partes em um contrato comprometem-se a submeter à arbitragem os litígios que possam vir a surgir, relativamente a tal contrato.

$\S 1^{\circ}$ A cláusula compromissória deve ser estipulada por escrito, podendo estar inserta no próprio contrato ou em documento apartado que a ele se refira. $\S 2^{\circ}$ Nos contratos de adesão, a cláusula compromissória só terá eficácia se o aderente tomar a iniciativa de instituir a arbitragem ou concordar, expressamente, com a sua instituição, desde que por escrito em documento anexo ou em negrito, com a assinatura ou visto especialmente para essa cláusula. ${ }^{2}$
\end{abstract}

Pelo exposto, vê-se que a Lei de Arbitragem não excluiu a aceitação tácita. O STJ decidiu que a aceitação tácita é possível quando a parte participa da arbitragem de tal modo que indica inequivocamente que concordou com a instituição da arbitragem, de acordo com decisão do caso entre L'Aiglon S.A. e Têxtil União (BRASIL, 2005).

No entanto, o STJ não aceita a existência do acordo de arbitragem se o requisito quanto à assinatura não foi cumprido ou, diferentemente, se a intenção de instituir a arbitragem não está em documento escrito (podendo ser o acordo ou qualquer outro documento que prove a vontade das partes). Ademais, tem decidido que, a falta de um acordo válido, afeta questões de ordem pública, como se depreende da seguinte decisão:

\begin{abstract}
SENTENÇA ARBITRAL ESTRANGEIRA. HOMOLOGAÇÃO. CLÁUSULA COMPROMISSÓRIA. AUSÊNCIA DE ASSINATURA. OFENSA À ORDEM PÚBLICA. PRECEDENTES DO SUPERIOR TRIBUNAL DE JUSTIÇA E DO SUPREMO TRIBUNAL FEDERAL. 1. "A inequívoca demonstração da manifestação de vontade de a parte aderir e constituir o Juízo arbitral ofende à ordem pública, porquanto afronta princípio insculpido em nosso ordenamento jurídico, que exige aceitação expressa das partes por submeterem a solução dos conflitos surgidos nos negócios jurídicos contratuais privados arbitragem." (SEC n ${ }^{\mathbf{o}}$ 967/GB, Relator Ministro José Delgado, in DJ 20/3/2006). 2. A falta de assinatura na cláusula de eleição do juízo arbitral contida no contrato de compra e venda, no seu termo aditivo e na indicação de árbitro em nome da requerida exclui a pretensão homologatória, enquanto ofende o artigo $4^{\circ}$, parágrafo $2^{\circ}$, da Lei $n^{\circ} 9.307 / 96$, o princípio da autonomia da vontade e a ordem pública brasileira. 3. Pedido de homologação de sentença arbitral estrangeira indeferido. (STJ - SEC: 978 GB 2006/0173771-1, Relator: Ministro HAMILTON CARVALHIDO, Data de Julgamento: 17/12/2008, CE - CORTE ESPECIAL, Data de Publicação: <!-DTPB: 20090305</br> --> DJe 05/03/2009</br> RIOBDCPC vol. 58 p. 160) (BRASIL, 2006).
\end{abstract}

Conclui-se que, nessa visão a lei brasileira é mais rígida que a o parágrafo 2 do art. II da Convenção, uma vez que esta não requer a assinatura nos casos em que a arbitragem está contida em uma troca não assinada de documentos. Outrossim, ao tornar inválida a invalidade da convenção arbitral uma questão de ordem pública, vai além do disposto na Convenção, que não prevê tal premissa. 
Assim, apesar da legislação brasileira não impedir a aceitação tácita, esta tem que ser provada em alguma forma escrita, tendo o STJ rejeitado a existência de aceitação oral que não se fez transcrita.

\subsection{Causas que impedem o reconhecimento e a execução}

$\mathrm{O}$ art. V da Convenção, que prevê os casos em que pode haver o indeferimento da execução, foi separado em dois parágrafos. O primeiro trata do que as partes podem alegar. O segundo lida com as hipóteses concernentes à ordem pública dos países contratantes, podendo ser arguidas pelo tribunal.

Inserir essas exceções causou um receio inicial aos doutrinadores, uma vez que o Estado poderia arbitrariamente indeferir a execução de uma sentença que não condiz com seus interesses, ainda mais quando ao Estado é permitido contratar com particular usando o disposto na Convenção de Nova Iorque.

Todavia, a prática mostrou que a Justiça estatal dos países que ratificaram a Convenção raramente aceita as hipóteses do art. V, 2, visto que distinguem a ordem pública nacional da internacional. Essa distinção se dá porque os assuntos de ordem pública nas relações domésticas são diferentes dos de ordem pública internacional.

A ordem pública é um conceito indefinido, abarcando elementos de ordem política, social, filosófica, econômica e moral. A consequência da manutenção da ordem pública prevê a formação de regras e princípios que garantam o bom funcionamento da estrutura do Estado, provendo ordem à sociedade.

As relações internacionais, por, em sua maioria, envolver várias localidades, estarão sob o regimento de diversos dos regramentos jurídicos nacionais. A arbitragem comercial internacional não está vinculada a nenhum ordenamento jurídico nacional, salvo estipulação expressa das partes nesse sentido. Contudo, ao se instaurar o processo de arbitragem, essencial se faz a observância à ordem pública internacional de cada país, devendo a arbitragem estar de acordo com os preceitos das normas imperativas e de ordem públicas aplicáveis na jurisdição, sob pena de ineficácia caso alguma jurisdição for contrária a algum aspecto da instauração, garantindo, assim, sua executividade.

Uma parte da doutrina defende a separação entre a ordem pública nacional e a internacional, condicionando a diferenciação ao contexto de um ordenamento jurídico nacional.

A ordem pública internacional estaria contida, então, na nacional, integrando, em conjunto, o direito nacional. Apesar de a ordem pública ser una e homogênea, há, nessa visão a possibilidade de dualizar seu conceito, pois se aplica diferentemente nos âmbitos interno e 
externo. A dualização é útil para o controle de legalidade da sentença arbitral estrangeira, interessando apenas o aspecto internacional da ordem pública interna (ALMEIDA, 2005).

$\mathrm{O}$ art. $2^{\circ}$ da Lei 9.307/96, ao permitir a escolha da lei a ser aplicada no processo arbitral pelas partes, afastando, assim, o critério até então vigente no ordenamento pátrio encampado no art. $9^{\circ}$ da Lei de Introdução do Código Civil - o da territorialidade - criou uma discussão sobre em qual modalidade de arbitragem (interna, internacional ou em ambas) este dispositivo se aplicaria.

A Lei de Arbitragem não faz distinção restringindo a aplicabilidade desse dispositivo a uma modalidade específica de arbitragem, podendo-se aplicá-lo, então, de acordo com a pura e fria interpretação da letra da lei, tanto nos processos arbitrais plurilocalizados como nos monolocalizados. A única distinção feita é aquela que se refere à sentença arbitral que, se proferida fora do território nacional, será considerada estrangeira estando, portanto, sujeita à homologação pelo Superior Tribunal de Justiça (após a Emenda Constitucional 45, de 2004) e, a contrario sensu, considerando-se sentença arbitral nacional, quando essa for proferida no território nacional.

O art. 39 da Lei de Arbitragem, o qual estabelece as hipóteses em que o reconhecimento e a execução de uma sentença arbitral devem ser indeferidas pelo STF determina, em seu inciso II, prevê que deve ser negada a homologação quando a decisão ofender a ordem pública nacional, qual seja, do Brasil. Desse modo, o texto do artigo não dá espaço para poder interpretar que a ordem pública internacional está abrangida.

O STJ não reconheceu, ainda, a mencionada distinção de ordens públicas, diferindo da interpretação da Convenção de Nova Iorque. Van den Berg ainda salienta que, ao não se apoiar no instituído pela Convenção, o Poder Judiciário brasileiro pode perder seu papel de liderança na arbitragem internacional, recomendando que o STJ estabeleça a diferença entre ordem pública nacional e internacional, contribuindo, assim, para a uniformização interpretativa da Convenção (BERG, 2013).

\subsubsection{Violação da ordem pública}

A ordem pública pode ser violada, segundo as decisões dos tribunais, por, basicamente, quatro motivos: ausência da parte, falta de imparcialidade e independência do árbitro, falta de justificação da sentença e desrespeito ao devido processo legal.

Essas motivações são sempre utilizadas, mas quase nunca obtêm sucesso. As decisões do Brasil seguem o mesmo padrão, mesmo com o texto do art. 39 da Lei $n^{\circ}$ 9.307/96 se referir, expressamente, à ordem pública nacional, uma vez que poderia aumentar o número de casos de recusa de execução por causa do uso de critérios nacionais para decidir. No 
entanto, o Poder Judiciário brasileiro parece diferenciar assuntos pertencentes às transações internacionais das nacionais, limitando, assim, seu controle sobre as decisões de indeferimento.

A ausência da parte pode constituir motivo para que a sentença não seja reconhecida e executada apenas quando a parte ausente não foi devidamente notificada dos procedimentos. O STJ confirmou essa visão no caso Union Europeéne de Gymnastique contra Multipole Distribuidora de Filmes (BRASIL, 2005), negando a alegação da empresa Multipole de não ter sido intimada para se defender, visto que houve a devida intimação por via postal em oposição à intimação por carta rogatória. Referida decisão do STJ se embasou no parágrafo único do art. 39 da Lei $n^{\circ} 9.307 / 96{ }^{3}$

A imparcialidade do árbitro requer que este não tenha interesses pessoais quanto à decisão a ser formulada, garantindo que haja segurança quanto a uma sentença justa. No entanto, ainda não foi objeto de análise pelo STJ.

Quanto à fundamentação da sentença, grande número de países aplica essa exigência, como se vê na formulação das leis de arbitragem, como a Lei Modelo da UNCITRAL - "The award shall state the reasons upon which it is based, unless the parties have agreed that no reasons are to be given or the award is an award on agreed terms under article 30" (UNCITRAL, 2004).

Entretanto, na hipótese de não estarem expostas as razões da sentença e esta ser considerada válida em seu país de origem, há divergências quanto à postura dos países em considerá-la válida, também, em seu território.

Dessa maneira, constata-se a importância da diferenciação entre questões de ordem pública nacional e internacional, já que, mesmo que não seja considerada válida em pela legislação nacional, poderia haver o reconhecimento de acordo com a ordem pública internacional.

\footnotetext{
Art. 39. Parágrafo único. Não será considerada ofensa à ordem pública nacional a efetivação da citação da parte residente ou domiciliada no Brasil, nos moldes da convenção de arbitragem ou da lei processual do país onde se realizou a arbitragem, admitindo-se, inclusive, a citação postal com prova inequívoca de recebimento, desde que assegure à parte brasileira tempo hábil para o exercício do direito de defesa. BRASIL. Lei n. 9.307, de 23 de setembro de 1996. Disponível em: <http://www.planalto.gov.br/ccivil_03/leis/L9307.htm>. Acesso em: 16 set. 2015.
} 
No Brasil não há essa diferenciação clara e expressa. Ademais, prevê, em seu art. 26, que a fundamentação da decisão é obrigatória. Assim, o STJ não aceitaria o reconhecimento de sentenças que não fossem devidamente fundamentadas, prejudicando a execução de sentenças estrangeiras válidas.

Por fim, o devido processo legal como motivador do não reconhecimento e execução pode ser fundamentado tanto de acordo com o art. V, parágrafo 2 quanto com o art. V, parágrafo 1, alínea b. A Lei de Arbitragem Brasileira prevê o mesmo, nos arts. 39, II e 38, III.

Havia um forte receio de que a Lei $\mathrm{n}^{\circ}$ 9.307/96, ao prever expressamente, em seu art. 39, II, que deve ser respeitada a ordem pública nacional, resultaria em variadas decisões de indeferimento de reconhecimento e execução de sentenças arbitrais, visto que defenderia unicamente o ponto de vista nacional e seus interesses. Contudo, como se depreende da análise exposta, a lei brasileira segue uma linha definida e limitada, favorecendo a construção de um entendimento uniforme.

\subsection{Causas que adiam a execução}

Está prevista, na Convenção de Nova Iorque, a possibilidade de o tribunal adiar sua decisão de execução caso a autoridade responsável julgar cabível, conforme o art. VI (BRASIL, 2002).

Ocorre que a lei brasileira não prevê qualquer dispositivo similar, formando uma lacuna a ser resolvida pela aplicação direta da Convenção de Nova Iorque pelo Poder Judiciário.

\subsection{Compatibilidade da Convenção de Nova Iorque e o princípio do dispositivo mais favorável}

O art. VII, parágrafo 1 da Convenção determina que a Convenção de Nova Iorque não anula os outros tratados sobre arbitragem, criando uma previsão de compatibilidade. Outrossim, permite que a parte fundamente seu pedido de execução de sentença estrangeira em outros tratados ou em legislação nacional, não tornando exclusiva a utilização da Convenção para tal fim.

Esse artigo mostra a intenção da Convenção, qual seja, a de assegurar a eficácia internacional da sentença arbitral, dando liberdade aos países para se utilizarem do método 
mais efetivo para cada caso. No entanto, quanto à uniformização das decisões, o disposto é um empecilho, visto que o país é livre para adotar o regime mais favorável, o que significa que diferentes decisões podem ser geradas.

As decisões do STJ que, em sua grande maioria, utilizam-se apenas da lei brasileira para fundamentar suas decisões, podem ser vistas como aplicadoras do regime mais favorável previsto no art. VII, parágrafo 1, visto que podem parecer mais favoráveis e atuais. No entanto, na maioria dos casos, a Convenção parece ser implicitamente referida e não considerada menos favorável do que a Lei de Arbitragem Brasileira (BERG, 2013).

\section{A CONVENÇÃO DE DUBLIN}

A importância da Convenção de Nova Iorque para o desenvolvimento da arbitragem no mundo é inquestionável, sendo um dos documentos mais importantes. Dificilmente uma outra Convenção conseguirá atrair a adesão de tamanho número de países signatários, fazendo com que sua aplicação assumisse características diferentes nas numerosas jurisdições, mas sem perder uma linha de racionalidade comum.

Entretanto, passaram-se 50 anos de sua promulgação. Desse modo, a formação de uma jurisprudência vinda dos países que a ratificaram mais cedo deu material de análise para as outras jurisdições sobre o reconhecimento e a execução de sentenças arbitrais estrangeiras, disseminando a aplicação da Convenção. Contudo, após esses 50 anos, questiona-se sobre a atualidade do conteúdo e se a aplicação prática é viável no contexto atual.

O professor Albert Jan van den Berg, uma das maiores autoridades no assunto, propôs uma modernização das disposições da Convenção de Nova Iorque, o que veio a ser denominada Convenção Minutada realizada em Dublin, na Irlanda. O que o professor busca alcançar com essa proposta é incentivar a uniformização da aplicação nas diversas jurisdições que são signatárias, aumentando a segurança jurídica da arbitragem internacional (BERG, 2008).

A proposta abarca mudanças na definição do escopo da Convenção, delimitando mais precisamente os propósitos. Assim, ao invés de definir, no art. I (BRASIL, 2002), de que trata de "sentenças arbitrais estrangeiras", expande para arbitragens internacionais, englobando as sentenças e as cláusulas arbitrais de natureza internacional. Muda, também, do conceito de "estrangeiro" para o de "internacional", a fim de respeitar as diferenças que muitas legislações mostraram quanto às arbitragens locais ou domésticas e internacionais. 
A Lei de Arbitragem Brasileira não prevê tais diferenças, tratando genericamente das arbitragens. A diferenciação ocorreu entre as sentenças arbitrais domésticas e as sentenças arbitrais estrangeiras, apenas, empregando o quesito puramente territorial para tanto. Como a lei em questão buscou alinhar o país à Convenção de Nova Iorque antes desta ser ratificada, foi essa solução "territorialista" (CARMONA, 2004) - simplista e objetiva - que inspirou a Lei $n^{\circ}$ 9.307/96, divergindo da lei francesa e da Lei Modelo da UNCITRAL que privilegiam os critérios de internacionalidade.

A Convenção de Dublin incorpora sua própria definição sobre o campo de incidência e aplicação, independendo da legislação de cada país para determinar se a Convenção pode ser aplicada ou não.

Além disso, quanto ao art. II (3) da Convenção de Nova Iorque - o qual levanta várias discussões no que tange à possibilidade do tribunal acabar não cumprindo o disposto por interpretar que a cláusula compromissória é nula - também foi objeto de discussão na Convenção de Dublin.

O professor entende, então, que se deve ser fiel à eficácia negativa da cláusula compromissória, prevalecendo a execução do exame de validade e eficácia prima facie, além de seguir a legislação aplicável no lugar onde a sentença arbitral deva ser proferida. Desse modo, prevalece do princípio norteador da arbitragem - o princípio kompetenz-kompetenz sendo o árbitro o primeiro juiz de sua própria competência, preservado o seu ulterior controle judicial quanto à eventual pedido de anulação de sentença arbitral ou de seu reconhecimento segundo o disposto na Convenção de Nova Iorque.

A análise exclusivamente prima facie da validade ou invalidade da cláusula compromissória, com algumas reservas, é posição firmada nos tribunais e na doutrina franceses. Embora não seja uma posição prevalente entre os países ratificadores, vem prevalecendo no Brasil (PINTO; FONSECA, 2003), garantindo a prioridade cronológica dos árbitros na análise de sua competência, sem prejuízo a uma eventual reapreciação pelo Poder Judiciário, conforme os arts. $8^{\circ}$ e 20 da Lei 9.307/96 (BRASIL, 1996).

Quanto aos motivos para a recusa de execução das sentenças arbitrais, previstas no art. V da Convenção de Nova Iorque, o professor propõe mudanças para que não haja espaço para outra interpretação, prevendo expressamente que os motivos listados para que uma sentença arbitral não seja reconhecida e executada sejam numerus clausus.

Ademais, estabelece que a parte que se opõe à execução da sentença arbitral pode alegar as matérias pertinentes se já tiver suscitado perante o Tribunal Arbitral anteriormente, salvo em hipóteses justificáveis. Desse modo, prevê-se o princípio da boa-fé, não podendo a 
parte se beneficiar de suas atitudes meramente protelatórias. No Brasil, prioriza-se o princípio da boa-fé, como mostra o leading case do STJ, no julgamento da Sentença Estrangeira Contestada 856, o qual reconheceu a existência de convenção de arbitragem porque a parte apresentou defesa nos autos, mas sem contestar a existência da cláusula compromissória (BRASIL, 2005).

No geral, foram essas as principais mudanças propostas pela Convenção de Dublin, podendo ser difícil sua aprovação, pelos países ratificadores, quanto a algumas posições antagônicas expostas. No entanto, importante salientar que tal Convenção busca a uniformização da aplicação da Convenção de Nova Iorque de 1958, baseando-se nas decisões feitas ao longo da história da Convenção, buscando solucionar os conflitos interpretativos mais pungentes.

\section{CONSIDERAÇÕES FINAIS}

O aumento do uso da arbitragem como saneadora de controvérsias advém de inúmeras vantagens em relação ao processo judicial. Dentre elas, possuem destaque o sigilo, não obrigando as partes a expor informações confidenciais, tais como os balanços, políticas adotadas, estratégias e know-how. Além disso, é célere, sendo os conflitos decididos por profissionais especializados no assunto, ao invés de serem julgados por juízes que possuem conhecimentos gerais.

A arbitragem traz outras vantagens, como a percepção de maior confiança quanto à decisão, visto que há maior confiabilidade no árbitro que as partes tiveram a chance de escolher, ao passo que, no juízo estatal, há desconfiança quanto à imparcialidade do juiz, uma vez que pode acatar os interesses da parte de mesma nacionalidade.

Quanto à onerosidade, disseminou-se a ideia de que o procedimento arbitral tem menores custos, até porque a controvérsia é mais rapidamente resolvida. No entanto, o custo depende das diligências que devem ser feitas para dirimir os conflitos, além dos custos com o número de árbitros e viagens destes, de peritos e das partes.

No contexto da arbitragem comercial internacional, a Convenção de Nova Iorque é, sem dúvidas, um dos documentos mais importantes, visto o impulso que proporcionou para o desenvolvimento da arbitragem.

A Convenção, ao proibir qualquer discriminação entre as decisões nacionais e estrangeiras, desburocratizou o processo de homologação das sentenças arbitrais, colaborando para que os litígios internacionais ganhassem soluções mais rápidas e eficazes. 
No entanto, a elaboração da Convenção ocorreu há mais de 50 anos, havendo dispositivos que necessitam ser atualizados, tendo em vista a mudança do cenário comercial mundial, tal como a incorporação de correspondências eletrônicas.

A Convenção de Dublin veio propor uma legislação mais direta e com menos lacunas, estreitando as possíveis interpretações com o intuito de unificar a jurisprudência arbitral.

Entretanto, pela análise da Convenção de Nova Iorque, constata-se que esta deu espaço para a interpretação segundo a lei nacional do país contratante, questionando-se se haveria de surgir uma atualização da Convenção ou apenas o desenvolvimento e uso das leis nacionais guiadas pelos objetivos da Convenção com atualizações segundo as práticas atuais do comércio internacional.

A Lei $n^{\circ}$ 9.307/96 trouxe os objetivos que basearam a Convenção de Nova Iorque, tendo uma enorme importância para o desenvolvimento da arbitragem no Brasil. Quanto às diferenças que parecem menos vantajosas que o disposto na Convenção, pode-se citar o requerimento do acordo escrito, não prevendo a forma tácita, podendo ser interpretada como mais rígida.

Além disso, a Lei de Arbitragem Brasileira não prevê todas as disposições sobre a recusa de execução e sobre as hipóteses de anulação da sentença arbitral, gerando um risco à legitimidade e segurança do laudo.

Por fim, não há distinção expressa sobre ordem pública nacional e internacional, colocando em risco a executividade da sentença se apenas for buscado o respeito à ordem pública nacional, como estabelecido na lei nacional.

A ratificação da Convenção de Nova Iorque pelo Brasil tornou a arbitragem mais confiável, mas não necessariamente por trazer dispositivos inovadores. Como se depreende do número de adeptos da Convenção, esta possui credibilidade, sendo importante para que o Brasil inspirasse confiança em relação à resolução de controvérsias no âmbito do comércio internacional por meio da ratificação.

A Lei no 3.907/96 inspirou-se nos objetivos da Convenção de Nova Iorque, mas não é uma cópia desta. A lei brasileira buscou trazer atualizações que condizem com a realidade do mercado mundial, como se depreende dos dispositivos semelhantes à atualização sugerida pela Convenção de Dublin.

Portanto, a aplicação da Lei n ${ }^{\circ}$ 9.307/96 nas sentenças arbitrais do STJ garante, mesmo que indiretamente, que os objetivos da Convenção de Nova Iorque sejam cumpridos, 
devendo-se permanecer atento às mudanças do comércio internacional e à uniformização jurisprudencial, a fim de que o Brasil continue se destacando como belle of the ball da arbitragem comercial internacional.

\section{REFERÊNCIAS BIBLIOGRÁFICAS}

ABOUL-ENEIN. The New York Convention of 1958 on the recognition and enforcement of Foreign Arbitral Awards: what needs to be done for the future. Revista de Arbitragem e Mediação. v. 5. n. 18. p. 101-107-, jul./set. 2008.

ALMEIDA, Ricardo Ramalho. Arbitragem Comercial Internacional e Ordem Pública. Rio de Janeiro: Renovar, 2005.

ARAUJO, Nadia. Análise das razões contrárias à adoção da Convenção. Revista de Arbitragem e Mediação. v. 5. n. 18. p. 42-49. jul./set. 2008.

ARROCHA, Katherine Gonzalez. The articles II and III of the New York Convention (NYC) and the experience of arbitral instrutions: the ICC experience. Revista de Arbitragem e Mediação. v. 5. n. 18. p. 86-100-, jul./set. 2008.

BERG, Albert Jan van den. Hypothetical Draft Convention on the International

Enforcement of Arbitration Agreements and Awards. Disponível em:

<http://www.arbitration-icca.org/media/0/12133703697430/explanatory_note_ajb_rev06.pdf>. . The New York Arbitration Convention of 1958. The Hague:

Kluwer, 1981.

. The New York Convention and its application by Brazilian

Courts. Revista de Arbitragem e Mediação. v. 37. 2013.

BRASIL. Código Comercial de 1850. Disponível em: <http://www.planalto.gov.br/ccivil_03/leis/L0556-1850.htm>. Acesso em: 05 nov. 2015.

Código de Processo Civil. Disponível em:

<http://www.planalto.gov.br/ccivil_03/leis/L5869.htm>. Acesso em: 20 set. 2015.

Constituição Federal do Brasil de 1824. Disponível em:

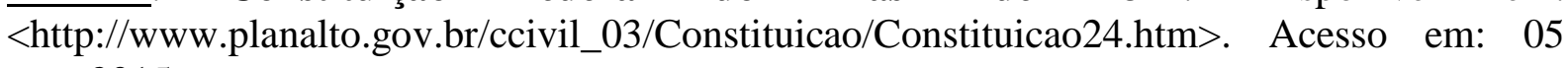
nov. 2015.

Decreto no 21.187 de 22.03.32. Clóvis Beviláqua. Parecer do Consultor Jurídico do Ministério das Relações Exteriores sobre o Protocolo relativo às Cláusulas Arbitrais de 
Genebra de 1923.

Decreto n. 3.900, de 26 de junho de 1867. Disponível em: <http://www.planalto.gov.br/ccivil_03/decreto/Historicos/DIM/DIM3900.htm>. Acesso em: 05 nov. 2015.

. Decreto-lei $n^{o}$ 4.657, de 4 de setembro de 1942. Disponível em: <http://www.planalto.gov.br/ccivil_03/decreto-lei/Del4657.htm>. Acesso em: 23 set. 2015.

. Lei n. 9.307, de 23 de setembro de 1996. Disponível em: <http://www.planalto.gov.br/ccivil_03/leis/L9307.htm>. Acesso em: 16 set. 2015.

. Sítio de Jurisprudência do STJ. Disponível em: <http://www.stj.jus.br/SCON/>. Acesso em: 03 ago. 2015.

. Recurso Especial no 1.231.554 - RJ (2011/0006426-8). (Nuovo Pignone v. Petromec), Rel. Min. Nancy Andrighi, DJe de 01.06.2011.

. SEC 856. Relator: DIREITO, Carlos Alberto Menezes. Data de publicação no DJe: 27/06/2005.

Disponível

em:

$<$ http://www.newyorkconvention1958.org/index.php?lvl=notice_display\&id=12 >. Acesso em: 14 out 2015.

. SEC: 978 . GB 2006/0173771-1. Relator: CARVALHIDO, Hamilton. Data de Publicação no DJe: 05/03/2009. Disponível em: <http://www.newyorkconvention1958.org/index.php?lvl=more_results\&look_ALL=1\&user_query=* \&autolevel1=1\&jurisdiction=10>. Acesso em: 15 nov. 2015.

CARMONA, Carlos Alberto. Arbitragem e processo. 2. ed. São Paulo: Atlas, 2004.

CARVALHO, Erick Leonardo Freire; LOPES, Marcelo Leandro Pereira. A lei de arbitragem e a Convenção de Nova Iorque à luz do STJ: efeitos da Emenda Constitucional $n^{\circ} 45$. Revista CEJ. Ano XVII, n. 60, p. 16-28. Brasília, maio/ago. 2013.

CONFERÊNCIA INTERNACIONAL AMERICANA, Sexta. Código de Bustamante. Disponível em: <http://www.faccamp.br/apoio/LuciaSirleneCrivelaroFidelis/direitoInternacional/cOdigo_de_ bustamente.pdf>. Acesso em: 10 out. 2015.

CONVENÇÃO DE VIENA SOBRE O DIREITO DOS TRATADOS. Arts. 31 e 32. Disponível em: <http://www.planalto.gov.br/ccivil_03/_ato2007- 
2010/2009/decreto/d7030.htm>. Acesso em: 20 nov. 2015.

CRETELLA NETO, José. Comentário à lei de arbitragem brasileira. Rio de Janeiro: Forense, 2007.

. Curso de arbitragem. Rio de Janeiro: Forense, 2004.

FIORATI, Jete Jane; MAZZUOLI, Valerio de Oliveira (Coord.). Novas vertentes do direito do comércio internacional. Barueri: Manole, 2003.

FIUZA, César. Teoria Geral da Arbitragem. Belo Horizonte: Del Rey, 1995.

FOUCHARD; GAILLARD. GOLDMAN. International Commercial Arbitration. Edited by Emmanuel Gaillard and John Savage. The Hague Boston : Kluwer Law International, 1999.

INTERNATIONAL CHAMBER OF COMMERCE - ICC. ICC Rules of Arbitration. Article 32: Award by Consent. Disponível em: <http://www.iccwbo.org/products-andservices/arbitration-and-adr/arbitration/icc-rules-of-arbitration/\#article_32>. Acesso em: 20 set. 2015.

LOBO, C. A. de Oliveira [et al]; ALMEIDA, Ricardo Ramalho (Coord.). Arbitragem

Interna e Internacional: questões de doutrina e da prática. Rio de Janeiro: Renovar, 2003.

MAGALHÃES, José Carlos de. A tardia ratificação da Convenção de Nova Iorque sobre a arbitragem: um retrocesso desnecessário e inconveniente. Revista de Arbitragem e Mediação. v. 5. n. 18. p. 24-41. jul./set. 2008.

MELLO, Celso D. Albuquerque. Curso de Direito Internacional Público. v. 1. 12. ed. Rio de Janeiro: Renovar, 2000.

NELSON, Timothy G. Into orbit: 50 years of global arbitration under New York Convention.

Revista de Arbitragem e Mediação. v. 5. n. 18. p. 73-85-, jul./set. 2008.

NEW YORK ARBITRATION CONVENTION. Contracting States - List of Contracting States. Disponível em: <http://www.newyorkconvention.org/list+of+contracting+states>. Acesso em: 26 set. 2015.

ORGANIZAÇÃO DAS NAÇÕES UNIDAS. A Carta das Nações Unidas. Disponível em: <http://nacoesunidas.org/carta/>. Acesso em: 24 set. 2015.

\section{Convenção sobre o Reconhecimento e a}

Execução de Sentenças Arbitrais Estrangeiras. Nova York, 1958. Disponível em: <http://www.planalto.gov.br/ccivil_03/decreto/2002/D4311.htm>. Acesso em: 24 set. 2015.

PINTO, José Emilio Nunes; FONSECA Rodrigo Garcia da. Convenção de New York: atualização ou interpretação? Revista de Arbitragem e Mediação. v. 5. n. 18. 2008. 
REDFERN, Alan; HUNTER, Martin. Law and practice of international comercial arbitration.

4. ed. Londres: Sweet \& Maxwell, 2004.

REZEK, Francisco. Direito internacional público: curso elementar. Francisco Rezek. 15. ed. São Paulo: Saraiva, 2014.

SUPERIOR TRIBUNAL DE JUSTIÇA. Resolução n. 9, de 4 de maio de 2005. Disponível em: <http://www.trtsp.jus.br/geral/tribunal2/Trib_Sup/STJ/Resol/9_05.html>. Acesso em 20 nov. 2015.

SUPREMO TRIBUNAL FEDERAL. Agravo Regimental na Sentença Estrangeira n.

5.206-7 (MBV v. Resil), Rel. Min. Sepúlveda Pertence, Plenário, julgado em 12.12.2001, DJ de 30.04.2002.

UNITED NATIONS COMISSION ON INTERNATIONAL TRADE LAW - UNCITRAL. Lei Modelo da UNCITRAL sobre Arbitragem Comercial Internacional - 1985. Com alterações adotadas em 2006. Disponível em: <http://cbar.org.br/site/wpcontent/uploads/2012/05/Lei_Modelo_Uncitral_traduzida_e_revisada_versao_final.pdf>.

Acesso em: 04 nov. 2015.

\section{Model Law on International Commercial Arbitration.}

1985. With amendments as adopted in 2006. Vienna: United Nations, 2008. Disponível em: <https://www.uncitral.org/pdf/english/texts/arbitration/ml-arb/07-86998_Ebook.pdf>. Acesso em: 02 set. 2015.

WALD, Arnoldo. A Convenção de Nova Iorque: o passado, o presente e o futuro. Revista de Arbitragem e Mediação. v. 5. n. 18. p. 13-23-, jul./set. 2008.

A interpretação da Convenção de Nova Iorque no direito comparado. Revista de Direito Bancário, do Mercado de Capitais e da Arbitragem. n. 22/366. ano 6. São Paulo, out./dez. 2003. 